(2014). Learning Analytics for Networked Learning Models. Journal of Learning Analytics, 1 (3), 191-194.

\title{
Learning Analytics for Networked Learning Models
}

\author{
Srećko Joksimović and Marek Hatala \\ School of Interactive Arts and Technology, Simon Fraser University, Canada \\ Dragan Gašević \\ Schools of Education and Informatics, University of Edinburgh, United Kingdom \\ sjoksimo@sfu.ca
}

\begin{abstract}
Teaching and learning in networked settings has attracted significant attention recently. The central topic of networked learning research is human-human and humaninformation interactions occurring within a networked learning environment. The nature of these interactions is highly complex and usually requires a multi-dimensional approach to analyze their effects. Therefore, the main goal of this research is the development of a theoretical model of networked learning that allows for a comprehensive and scalable analysis of how and why learners engage in collaboration in networked communities. The proposed research method, anticipated research outcomes, and contributions to the learning analytics field are discussed.
\end{abstract}

KEYWORDS: Networked learning, connectivism, community of inquiry, SNA, content analysis

\section{MOTIVATION}

Networked learning, an emerging paradigm in educational research with theoretical, pedagogical, and practical importance (Dirckinck-Holmfeld, Hodgson, \& McConnell, 2012), is defined as a learning approach that relies on information and communication technologies in order to support connections among learners, between learners and teachers, and between learners and learning resources (Goodyear, 2004). The use of technology impacts every aspect of learning and mediates connections within a learning community. Therefore, the main goal of networked learning research is to understand how various technological affordances can influence pedagogy and learning design in order to foster deep and meaningful learning (Dirckinck-Holmfeld et al., 2012).

Although research in the area of network learning has attained significant attention, the literature review conducted indicates that most of the current studies are based on the use of crude proxies of underlying processes (e.g., the frequency of facilitator and learner postings) (Kop, 2011; Yeager, HurleyDasgupta, \& Bliss, 2013). Here, we propose novel learning analytics methods for assessing the learning processes in networked learning environments. The main goals of this research are 1) the development of a theoretical model of networked learning that offers a definition of its constructs along with their mutual relations; 2) operationalization of the measurement of those constructs; and 3) automated methods that can scale up the applicability of the proposed model. 
(2014). Learning Analytics for Networked Learning Models. Journal of Learning Analytics, 1 (3), 191-194.

\section{METHODS}

Following the main assumptions of connectivism (Siemens, 2005), and relying on the existing body of research into the Community of Inquiry (Col) model (Garrison, Anderson, \& Archer, 1999), and the theory of transactional distances (Moore, 1993), we are developing a theoretical model for studying networked learning and teaching in informal settings. The general approach for the development, operationalization, and validation of the constructs of the proposed model will utilize both quantitative (e.g., social network and quantitative content analysis) and qualitative (e.g., discourse analysis) techniques in order to describe the complexity of learning processes in online learning networks (Gašević, Kovanović, Joksimović, \& Siemens, 2014). The model is designed on the assumptions that knowledge resides in a network, and that social and technical aspects are important factors for information flow and knowledge building processes within a network (Siemens, 2010). In developing constructs of the proposed model and relations between those constructs, we will further redefine existing models of online education, primarily the Col model (Garrison et al., 1999) and the theory of transactional distances (Moore, 1993), in order to address the requirements of networked learning research. Relying on quantitative methods of social network analysis (SNA) and (automated) content analysis, and qualitative methods of contextual analysis, we aim to inform and validate the theory and enable automated operationalization of the proposed constructs.

\section{RESULTS}

In our most recent studies, we analyzed informal learning networks emerging from learner interactions within various media (i.e., Twitter, Facebook, and blogs) used in distributed massive open online courses (MOOCs) and from learner-generated content within those networks. In Skrypnyk, Joksimović, Kovanović, Gašević, \& Dawson (in review) study, we relied on the well-established SNA methods (e.g., betweenness centrality and modularity analysis) in order to examine the role of course participants in the information flow within a network of learners emerging from Twitter-based communication. The study confirmed that, although course facilitators still play an important role (especially in the beginning of a course), the information flow and knowledge building processes also depend on network-directed learners willing to engage in and facilitate interaction and knowledge sharing with their peers. Within our ongoing research, we aim to infer the "quality of contribution" of emerging facilitators. Specifically, utilizing methods of automated content analysis of socially shared discourse, we investigate whether influential learners contribute to the network knowledge base or rather tend to broadcast information provided by course facilitators.

In the Joksimović, Dowell, et al. (2015) study we analyzed the importance of various contextual factors (i.e., language use, time, media, and learner activity) on the accumulation of social capital. In order to reveal underlying cognitive processes of course participants, we analyzed discourse students constructed and shared by social media. We applied automated linguistic analysis through measures of text cohesiveness (Graesser, McNamara, \& Kulikowich, 2011). Social capital was measured using several structural properties of the social network - i.e., degree, closeness, betweenness, and eigenvalue 
(2014). Learning Analytics for Networked Learning Models. Journal of Learning Analytics, 1 (3), 191-194.

centrality. We found that better understanding the development of social ties and network structures required both shallow and complex text analysis. In our further research, we will investigate different instructional scaffolds and technological affordances that will guide students to develop necessary skills (i.e., "new media literacies"; Dawson \& Siemens, 2014) for learning in networked environments.

We recently proposed a novel analytic approach that integrates automated keyword extraction, graph theory, and in-depth qualitative analysis in order to provide better insight into topics being discussed among the course participants (Joksimović, Kovanović, et al., 2015). The proposed approach allowed for validations of certain ideas of connectivism. For example, we found that the technological affordances of social media used (e.g., Twitter vs. Facebook vs. blogs) and learners' interests have the major impact on socially constructed knowledge. Our ongoing research also examines how different social groups, emerging from interactions within various media, shape socially constructed knowledge in a distributed MOOC.

\section{CONTRIBUTION TO LEARNING ANALTYICS}

Given the interdisciplinary nature of the proposed research, contributions can be observed from theoretical and practical perspectives. Primarily, the proposed research will provide network learning researchers with a theoretical framework to help understand interactions that occur in networked learning communities. Having in mind the scope of this research, educational practitioners and researchers can benefit from the anticipated research outcomes, since the proposed model will advance our understanding of how technological affordances can foster learning in informal learning settings.

\section{REFERENCES}

Dawson, S., \& Siemens, G. (2014). Analytics to literacies: The development of a learning analytics framework for multiliteracies assessment. The International Review of Research in Open and Distance Learning, 15(4). Retrieved from http://www.irrodl.org/index.php/irrodl/article/view/1878

Dirckinck-Holmfeld, L., Hodgson, V. E., \& McConnell, D. (2012). Exploring the theory, pedagogy and practice of networked learning. New York: Springer.

Garrison, D., Anderson, T., \& Archer, W. (1999). Critical inquiry in a text-based environment: Computer conferencing in higher education. The Internet and Higher Education, 2(2-3), 87-105.

Gašević, D., Kovanović, V., Joksimović, S., \& Siemens, G. (2014). Where is research on massive open online courses headed? A data analysis of the MOOC research initiative. The International Review of Research in Open and Distance Learning (IRRODL), 15(5). http://www.irrodl.org/index.php/irrodl/article/view/1954.

Goodyear, P. (2004). Advances in research on networked learning (Computer-Supported Collaborative Learning, Vol. 4). Norwell, MA, USA: Kluwer Academic Publishers.

Graesser, A. C., McNamara, D. S., \& Kulikowich, J. M. (2011). Coh-Metrix providing multilevel analyses of text characteristics. Educational Researcher, 40(5), 223-234. 
(2014). Learning Analytics for Networked Learning Models. Journal of Learning Analytics, 1 (3), 191-194.

Joksimović, S., Dowell, N., Skrypnyk, O., Kovanović, V., Gašević, D., Dawson, S., \& Graesser, A. C. (2015). How do you connect? Analysis of social capital accumulation in connectivist MOOCs. Proceedings of the 5th International Learning Analytics and Knowledge (LAK) Conference.

Joksimović, S., Kovanović, V., Jovanović, J., Zouaq, A., Gašević, D., \& Hatala, M. (2015). What do cMOOC participants talk about in social media? A topic analysis of discourse in a cMOOC. Proceedings of the 5th International Learning Analytics and Knowledge (LAK) Conference.

Kop, R. (2011). The challenges to connectivist learning on open online networks: Learning experiences during a massive open online course. The International Review of Research in Open and Distance Learning, 12(3), 19-38.

Moore, M. G. (1993). Theory of transactional distance. Theoretical Principles of Distance Education, 22.

Siemens, G. (2005). Connectivism: A learning theory for the digital age. International Journal of Instructional Technology and Distance Learning (IRRODL), 2(1), 3-10.

Siemens, G. (2010). Teaching in social and technological networks. Connectivism. Disponível em. http://www.connectivism.ca

Skrypnyk, O., Joksimović, S., Kovanović, V., Gašević, D., \& Dawson, S. (in review). Roles of course facilitators, learners, and technology in the flow of information of a cMOOC. The British Journal of Educational Technology, Special Issue on MOOCs.

Yeager, C., Hurley-Dasgupta, B., \& Bliss, C. A. (2013). cMOOCs and global learning: An authentic alternative. Journal of Asynchronous Learning Networks, 17(2), 133-147. 